\title{
SARS-CoV-2 - an update in virology: A Narrative Review
}

\author{
Mohabeer $\mathrm{P}^{1}$, Banerjee ${ }^{2 *}$, Kashyap $\mathrm{A}^{3}$, Shukla $\mathrm{A}^{4}$, Robinson $\mathrm{J}^{5}$, Ramdhan $\mathrm{ND}^{6}$
}

\section{*Corresponding author:}

Dr. Indrajit Banerjee

Associate Professor, Department of Pharmacology, Sir Seewoosagur Ramgoolam Medical College, Mauritius

Email: indrajit18@gmail.com ORCID

\section{Information about the article:}

Received: Oct 30, 2020

Accepted: Dec 24, 2020

Published online: Dec 31, 2020

\section{Cite this article:}

Mohabeer P, Banerjee I, Kashyap A, Shukla A, Robinson J, Ramdhan ND. SARS-CoV-2 - an update in virology: A Narrative Review. Journal of Biomedical Sciences. 2020;7(2):77-87

\section{Publisher}

Nepal Health Research Society, Bahundhara -6, Gokarnesowor Municipality, Kathmandu, Nepal eISSN 2382-5545, ISSN 2676-1343 (Print)

(C) The Author(s). 2020

Content licensing: CC BY 4.0

\section{ABSTRACT}

\section{Background}

SARS-CoV-2 is the highly infectious new coronavirus, which has been associated with the pandemic COVID-19. The majority of those pathogenic coronaviruses are benign, namely HCoV-229E, HCoV-NL63, HCoV-OC43 and $\mathrm{HCoV}-\mathrm{HKU} 1$, and they have been linked to common cases of flu. Two of these viruses namely SARS coronavirus and MERS coronavirus are known to have caused more severe infections. Based on phylogenetic analysis, the Coronaviruses are divided into four groups, which are: Alpha-CoV, Beta -CoV, Gamma-CoV, and Delta -CoV. The Beta- $\mathrm{CoV}$ genus is further classified into four lineages, which are referred to as Groups A, B, C, and D. At the genomic level, SARS-CoV-2 has been identified to match with the lineage $\mathrm{B}$ of Beta coronavirus. This infection affects the respiratory tract, mainly the lungs' alveoli, and can cause a wide variety of symptoms ranging from discharge from the nose and a sore throat to respiratory distress, septic shock, and failure of multiple organs. To date, millions of people have been affected by the virus. The current mortality rate is around 6\%. Early diagnosis is essential to prevent the spread of the infection. An extensive literature review was done using Pubmed, Medline, Pubmed Central, Embase, Goggle Scholar databases from January 20, 2020, till October 20, 2020.

\section{Conclusion}

COVID-19 is the third outbreak of a pathogenic human coronavirus, after MERS and SARS. Its high rate of transmissibility has taken a toll on citizens' personal and professional lives globally. The peculiarities of SARS-CoV2, regarding its genomic uniqueness and the role of Malayan pangolins as intermediate hosts, still demands more research to determine the degree to which they partake in the generation of the pathogenicity and infectiousness of the virus.

\section{Keywords}

ACE2 receptor, COVID-19, Coronavirus, Middle East Respiratory Syndrome Coronavirus, Microbiology, Severe Acute Respiratory Syndrome Virus 


\section{Background}

Coronavirus infectious disease 2019 (COVID-19), formerly referred to as the Wuhan Coronavirus or 2019 novel coronavirus by Chinese researchers, has been the third outbreak of a pathogenic beta coronavirus disease [1]. On December 29, 2019, hospitals in Wuhan, Southern China, isolated 4 cases of "pneumonia of an unknown etiology", via the surveillance mechanism, which was implemented during the emergence of SARS [2]. At the present date (October 24, 2020), the world continues to witness the exponential rise in the number of confirmed cases of COVID-19 to 42,055,863 with 1,141,567 deaths as reported by WHO [3]. The causative agent of this pneumonia of an unknown etiology was subsequently named SARS-CoV-2, while the disease was termed COVID-19 by the International Committee on Taxonomy of Viruses [1]. SARS-CoV-2 is the seventh coronavirus that has been established as a highly infectious pathogenic virus to humans. This new virus originates from a family of viruses named the Coronaviridae. Based on phylogenetic analysis, new SARS-CoV-2, and lineage B of Beta coronavirus were found to share matching genomes [4]. It has more specifically been outlined as being a member of Clade 2 of the subgenus Sarbecovirus.

Severe acute respiratory syndrome (SARS) appeared in China in 2002-2003. It was associated with the human SARS CoV, whereas Middle East respiratory syndrome (MERS), seeded from MERS $\mathrm{CoV}$, gave rise to an epidemic in the Middle East in 2012 [1]. After the emergence of its precedents, SARS and MERS, COVID19 now joins the list of zoonotic coronavirus diseases. The genome of SARS-CoV-2 has an $89 \%$ homology with that of the bat SARS-like- CoV ZXC21, implying that bats constitute the natural reservoirs of SARS-CoV-2. However, some articles elaborate that bats, the suggested primary reservoirs of SARS-CoV-2, were not being sold at the Huanan seafood market, suggesting a high possibility of an unknown animal as being the Intermediate host, which may have been sold in the market, hence infecting the terminal hosts [2]. Malayan Pangolins have been identified as a potential intermediate host contributing to the spread of COVID-19 [5].

Owing to its high transmissibility rate, SARS-CoV-2 has given rise to a more significant reproductive number when compared to that of its precedents, SARS and MERS. SARS-CoV-2 spreads by near physical contact to an already infected patient, particularly upon exposure to respiratory droplets produced by coughing, sneezing, and aerosols. Spread via microdroplets has also been identified as another mode of transmission of COVID-19. The average period of incubation of the virus is 5.1 days; the disease manifests as fever, dry cough, dyspnea, sneezing, and a painful throat in most patients. However, in 20-25\% of the COVID-19 cases, patients with no upper respiratory symptoms may have diarrhea. As the disease progresses to a critical stage, it manifests as pneumonia, metabolic acidosis, bleeding, and septic shock [6].

This narrative review aims to study the nomenclature and classification SARS-CoV- 2, its genome, source and mode of infection, incubation period, and laboratory diagnosis, with a comparison of Transmission rate and Ro of SARSCoV, MERS-CoV, SARS- CoV-2.

\section{Methods}

An extensive literature review was done using Pubmed, Medline, Pubmed Central, Embase, Google Scholar databases from January 20, 2020, till October 20, 2020. A combination of Keywords "COVID-19", OR "2019nCoV” OR "SARS-CoV-2”, OR “Coronavirus”, OR AND "virology" were used during the literature survey.

\section{Results}

\section{Nomenclature and classification}

The SARS-CoV-2 virus originates from Coronaviridae $(\mathrm{CoV})$ family of viruses. The Coronavirus $(\mathrm{CoV})$ owes its name to the arrangement of the $\mathrm{CoV}$ virions, which project from the surface of the virus membrane giving the virus a close resemblance to that of a crown when first observed under the electron microscope. Thus, hence it being named Coronavirus, after the Latin word "Corona", which signifies a crown [5]. The coronaviruses are classified under the order Nidovirales and suborder Cornidovirineae. The word "Nidovirales" derives its origin from the word 'Nido', which means nest, owing to their aptness to constitute a nested pattern of subgenomic mRNA [6].

Letovirinae and Orthocoronavirinae are the two subfamilies that constitute the Coronaviridae family of viruses. Based on its phylogenetic study and genomic structure, Orthocoronavirinae is subclassified into four groups: Alpha-CoV, Beta -CoV, Gamma-CoV, and Delta -CoV [6]. The Beta- CoV genus is further classified into four lineages: Groups A, B, C, and D (5). SARS-CoV-2 has been identified at the genomic level to match with the lineage B of Beta coronavirus [7].

Severe Acute Respiratory Syndrome (SARS-CoV), the Middle East respiratory syndrome (MERS-CoV), HCoVOC43, and HCoV-HKU1 belong to the Beta Coronavirus lineage same as SARS CoV-2. At the same time, the other two benign human coronaviruses, HCoV-229E, NL63 have been classified under Alpha coronavirus [5]. Upon profound research of the genus Beta coronavirus, it was found that it could be further classified into five subgenera, namely Sarbecovirus, Hibecovirus, Nobecovirus, Merbecovirus, and Imbecovirus. SARS$\mathrm{CoV}-2$ form part of the Clade 2 of the subgenus Sarbecovirus. The first clade of Sarbecovirus englobed two strains of viruses associated with SARS-CoV belonging to the Rhinolophus species in Bulgaria and Kenya. The third clade constituted the SARS-CoV strains obtained from humans and viruses that genetically 
resemble SARS-like coronaviruses found in bats, procured from Southwestern China [4].

\section{Morphology of the virus}

The coronavirus has a diameter ranging from $65-125 \mathrm{~nm}$ [8]. This enveloped virus has a single-stranded positivesense RNA, measuring 26-32 kilobases, making it the RNA virus in possession of the largest known genome [5]. The outermost layer of this virus is the Spike glycoprotein molecules (S protein). It is made up of 2 subunits, mainly, namely S1 and S2. S1 facilitates the attachment of the offender to the host cells, while S2 aids in the fusion of the viral envelope to the cell membrane of the host cells [4].

However, it was discovered that most genetic sequence variation had been shown by $\mathrm{S}$ protein than any other structural protein within the coronavirus species [9]. Moreover, research suggests that this spike protein is responsible for determining the host tropism and transmission rate of SARS-like viruses [10]. According to research done on the host jump of coronaviruses, the SARS-CoV model was studied to investigate the possibility of any cross-species transmission. This research studied mutations in the S protein layer of SARS$\mathrm{CoV}$ as a means of facilitating the interspecies spread of the disease. Among the various genetic mutations studied, one of them was substituting the civet-specific K479 and S487 amino acids by the human-specific N479 and T487 in the S protein, which increased its affinity to bind to the ACE2 receptor. These mutations were also demonstrated in studies performed on mouse-adapted viruses. Thus, these changes in the $\mathrm{S}$ protein were found to be faciliatory to the interspecies spread of SARS-CoV [10].

Moreover, other studies suggested that the new coronavirus's enhanced virulence and transmission rate in comparison with SARS-CoV could be attributed to a possible genetic recombination event at its Spike glycoprotein layer [8]. The coronavirus constitutes two structural proteins: the Integral Membrane Glycoprotein (M) and Small Membrane Protein (E). M protein has been established to be crucial for the synthesis of corona-like particles. It has been suggested that it has a significant role in assembling the virus particle, together with the $\mathrm{E}$ protein [8].

Hemagglutinin-Esterase Glycoprotein (HE), the function of which matches that of the $\mathrm{S}$ protein, is possessed by the lineage of Alpha coronaviruses [5]. These coronaviruses perform hemagglutination more efficiently than those that do not contain the HE glycoprotein. Within the coronavirus species, only Bovine Coronavirus (BCV) uses the HE protein to infect hosts. However, HE glycoprotein's role in the pathogenicity of other coronaviruses has not yet been established [9].

The Nucleocapsid Protein (N) is a phosphoprotein molecule, about 50-60 KDa in size. In combination with CoV's RNA genome, it has been seen to form a helical nucleocapsid (RNP), which safeguards the genome against ribonucleases. $\mathrm{N}$ protein's aptness to bind to membranes and phospholipid molecules makes the formation of viral particles easy. Moreover, mutations within the $\mathrm{N}$ protein hold the power to affect the CoV's stability or viability [9].

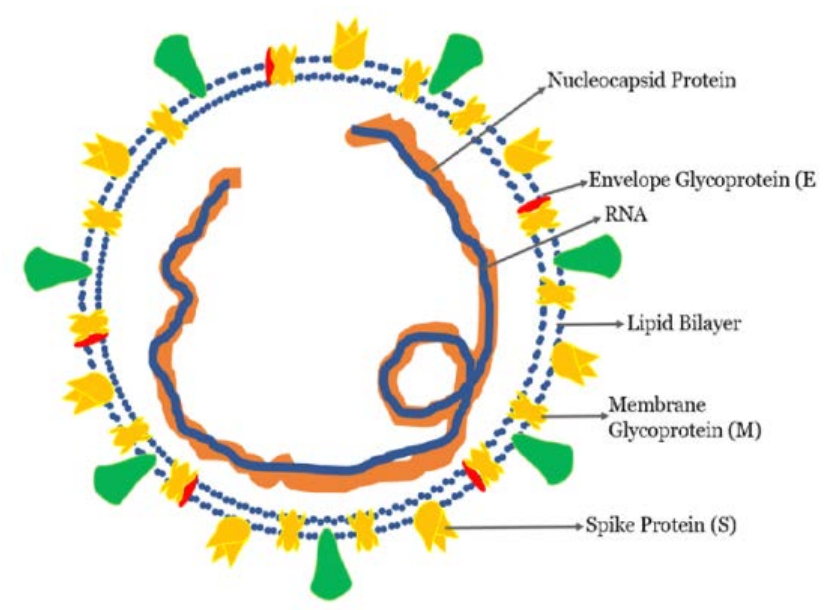

Figure1: Structure of human Coronavirus Adapted from: Shereen MA et al., J Adv Res. 2020 [5]

\section{Genome of $\mathrm{CoV}$ and SARS-CoV-2}

CoV's genome is a positive sense, single-stranded RNA, which functions as an mRNA, hence making it infectious. The genome constitutes about seven to ten functional genes encoded by reading frames at 51 and 31 ends. These are arranged in the order of $5^{\prime}$-polymerase-(HE)-S-E-M and other genes coding for non-structural proteins being interspersed in between [9]. Genes for main structural proteins, namely the $\mathrm{S}, \mathrm{E}, \mathrm{M}$, and $\mathrm{N}$, occur in $5^{\prime}$ to $3^{\prime}$ for all coronaviruses [11]. The arrangement of non-structural protein genes between the regular arrangement of functional genes has been found to vary significantly among various $\mathrm{CoV}$ species [9].

The new SARS-CoV-2 is structurally similar to that of the typical coronavirus. It is a monopartite positive-sense single-stranded RNA, constituting 29,903 nucleotides, making it the second biggest RNA genome researched [6]. At the 5' and 3' ends of the virus genome, two untranslated regions are found, along with eleven open reading frames encoded for 27 proteins [6,12]. Two-thirds of the genome make up the first ORF (ORF1/ab), which encode for 16 non-structural proteins, and the last third consists of genetic material for four structural proteins and at least six accessory proteins, namely orf3a, orf6, orf7a, orf7b, orf8, and orf10 [12-15]. Research also suggests the presence of eight accessory proteins (3a, 3b, p6, 7a, 7b, 8b, 9b, and orf14) [12].

ORF1/ab constitutes 21,290 nucleotides, and it is found to encode for either of the two proteins, namely the replicase proteins pp1a, ranging from Non- structural protein (nsp) 
1 to nsp11 or pp1ab, ranging from nsp1 to nsp16. The function of certain nsp's have been outlined; nsp1 arrests host response against the virus, nsp3 behaves as a papainlike protease, nsp5 acts as a 3C- like protease domain, nsp7 combines with nsp8 yielding a primase, nsp9 contributes to binding of DNA/RNA, nsp12 is an RNAdependent RNA polymerase, and nsp13, nsp14 and nsp15 function as helicase, 30-50 exonuclease and poly (U)specific endoribonuclease respectively. The rest of the non-structural proteins contribute to transcription and replication of the virus genetic material $[13,16,17]$. The structural proteins possessed by SARS-CoV-2 match that of a typical $\mathrm{CoV}$, namely spike glycoprotein (S), matrix protein $(\mathrm{M})$, an envelope protein $(\mathrm{E})$, and nucleocapsid protein $(\mathrm{N})$ [13-15].

\section{Comparing the genome of SARS-CoV-2, MERS and SARS}

Investigators suggest that SARS-CoV-2 shares $88 \%$ similarity to two of the bat-derived severe acute respiratory syndrome (SARS)-like coronaviruses, bat-SLCoVZC45 as well as bat-SL-CoVZXC21. SARS-CoV-2 was about $79 \%$ and $50 \%$ identical to SARS and MERS, respectively [18]. When protein sequences of new coronavirus was aligned to those of its precedents, SARS$\mathrm{CoV}$ and SARS-like coronaviruses, 380 amino acids were found to be substituted between these viruses [6].

Out of 380 substitutions, 348 mutations were found to be in the non-structural proteins, namely (ORF1ab, 3a, 3b, 7a, 7b, 9b, and ORF14), 27 mutations in the spike glycoprotein, and lastly, five mutations in the Nucleocapsid protein. $\mathrm{E}$ and $\mathrm{M}$ proteins have not undergone any amino acid substitution in SARS-CoV and SARS-like coronaviruses [6].

It has been observed that SARS-CoV-2 and SARS-CoV act on the same receptor hACE2, to enter the cells [19].

This could be attributed to the similar binding affinities of their receptor-binding domains. Despite the 27 mutations observed in the spike glycoprotein, the receptor-binding motif, which interacts with hACE2, was conserved, such that the host tropism would not be affected [6]. Compared to SARS-CoV and MERS-CoV, SARS-CoV-2 was found to have a longer spike protein [18]. Similarities in the RBD and RBM of the spike glycoprotein of SARS-CoV-2 and SARS-CoV were observed, while SARS-CoV-2 RBM showed some residual genetic material eases its binding to human ACE2 [6].

The RBD domain of the S1 is also unchanged, except for some distinctions in some amino acids present in the outer subdomain, which facilitate the attachment of SARSCoV-2 to the host receptor. The S1 and S2 subunits of SARS-CoV-2 spike protein are $70 \%$ and $99 \%$ similar to that of the SARS-like CoVs (SL-CoVZXC21 and ZC45) and to the human SARS-CoV, respectively [13]. Some research suggests that the difference its $S$ protein and its high infectiousness are attributed to the evolution of
SARS-CoV-2 through natural selection for attaching to the ACE2 receptor [20]. However, a novel polybasic cleavage site and predicted O-linked glycans were found to differentiate SARS-CoV-2 from its precedent viruses [20]. Walls et al.,2020 established the revelation of a furin cleavage site insertion at the S1-S2 junction of the spike glycoprotein in SARS-CoV-2 [21]. This feature is not present in SARS-CoV, and hence it implicates its role in the increased infectiousness of the novel coronavirus [20].

The origin of this furin cleavage site is still unclear and as is its role in the adaptation of new coronavirus to humans or other hosts [22], but as pointed out by some researchers, this new cleavage site facilitates the Smediated entry of SARS-CoV-2 into the VeroE6 or BHK cells, and this may imply its role in the expansion of host tropism for this novel Beta coronavirus. A similar phenomenon has been reported previously in increasingly pathogenic avian influenza viruses and the Newcastle disease virus [23, 24]. The isolation of a similar insertion from wild bats strongly points towards the novel Beta coronavirus's natural animal origin [22]. Another feature of SARS-CoV-2 which sets it apart from its precedents is the ORF3. The ORF3b of new coronavirus, which contributes to the virus's pathogenicity and its inhibitory function in the expression and signaling of interferon (IFN), is found to have some deletion mutations [25, 26]. However, this deletion mutation has not affected the viral replication in the laboratory tests [6]. Moreover, a new protein has been found in Open Reading Frame 3b of the new coronavirus. However, its role in the virus's pathogenicity is unclear [13].

\section{Comparison of Transmission rate and Ro of SARS- CoV, MERS-CoV, SARS- CoV-2}

SARS-CoV infected 8098 individuals across 26 countries, contributing to a mortality rate of $9 \%$, while the new SARS-CoV-2 to date led to a mortality rate of $6 \%$. Despite having a decreased mortality rate, SARS-CoV-2 still has higher pathogenicity than SARS-CoV because it has infected more than 6 million individuals worldwide [8]. This is indicative of a higher transmission rate of the COVID-19 as compared to SARS. The mortality rate of MERS-CoV is 34.4\%, having infected more than 2428 individuals and caused 838 deaths, yet its reproductive number (Ro) is 0.7 compared to SARS-CoV-2, which has Ro of 2.0-2.5, as reported per the WHO [27]. However, as per another review, the reproductive number of COVID19 has been estimated to be at a mean value of 3.28 and a median value of 2.79 , which exceeds that of the WHO report [28].

The reproductive number of SARS-CoV ranges between 1.7 to 1.9, which is higher than that of MERS-CoV [8].

This is suggestive of the fact that MERS-CoV has a lower transmission rate, which could be attributed to the more severe clinical picture caused by this virus as compared to SARS-CoV-2 and SARS-CoV. It requires earlier 
hospitalization, which further decreases the risk of community spread and increases the risk of nosocomial spread [28].

\section{Source of infection of $\mathrm{CoV}$}

Alpha- CoV and Beta- CoVs generally originate from mammals compared to gamma- CoVs and Delta-CoVs, which are of avian origin [5]. It has been found that all coronaviruses pathogenic to humans fall under the category of alpha and Beta coronavirus genera. These also constitute coronaviruses, which are mainly of bat origin. Unlike CoVs originating from Alpha-CoV and Beta -CoV genera, the other CoVs like 229E, OC43, NL63, and HKU1 are not severely pathogenic to human beings. However, they can result in mild diseases in immunocompromised individuals. As compared to SARS$\mathrm{CoV}$ and MERS-CoV, these viruses are not maintained in zoonotic reservoirs [5].

\section{Source of infection of SARS-CoV-2}

After SARS and MERS, COVID-19 joins the list of zoonotic coronavirus diseases, which facilitates man-toman transmission. The genome of the new coronavirus has an $89 \%$ homology with bat SARS-like- CoV ZXC21. This suggests that it originates from the bat.

However, some evidence has been provided to indicate the possibility that the new member of the CoV family could be a recombinant coronavirus from that which is currently present in both snakes and bats. This has been highlighted via their comparison and synonymous codon usage bias across various animal species [29].

Recombination has been a mechanism of evolution for coronaviruses, namely SARS-CoV and MERS-CoV [30], yet the presence of any recombination events in SARSCoV-2 has not been comprehended. [6] Initial research has indicated the possibility of this method of evolution [30]. However, other research indicates that the recombination events are more intricate, allowing it to occur in SARS-CoV-2 instead of the bat coronaviruses. Hence this suggests that the virus might have emerged owing to other reasons besides recombination [4].

A hypothesis has emerged which speculated that the new coronavirus was synthetically engineered in a laboratory in Wuhan has surfaced. However, there has been no proof to substantiate this speculation [31].

\section{Mode of transmission of SARS-CoV-2}

As per the research conducted on the genomic description, comparison, and epidemiology of this novel Coronavirus, the man to man spread of the new Coronavirus has been established [4]. The subjects used for this research have been patients who had visited the Huanan seafood market in Wuhan during the outbreak of COVID-19. One of the subjects had not visited the market, yet he stayed in a hotel that was in close proximity to the market. Moreover, clusters of infected members within a family, and medical professionals, who have been exposed to these patients confirmed that the SARS-CoV-2 is spreading from man to man since people were still being infected despite no exposure to the source of infection [4].

It has been emphasized that SARS-CoV-2 spreads not only by close contact with an infected patient but also upon exposure to respiratory droplets, produced by coughing, sneezing, and aerosols, which make their way inside the lungs, when inhaled through the nose or the oral cavity [8]. A study of the normal human sneeze reveals that the largest droplets deposited within 1 to 2 meters from the position of the person, as compared to the smaller droplets which could remain suspended in the air for a few seconds and minutes, or even travel 6-8 $\mathrm{m}$ away from the vicinity of where the sneeze occurred [32]. Hence the presence of a microdroplet particle, which measures less than 10 micrometers in diameter, can drift in the air, resulting in potential infections via viral transmission. This fact has been illustrated by the Japanese Association for Infectious Disease's research, which reported that infections via microdroplets should be established as another mode of transmission of COVID-19 [33].

Initially, SARS-CoV was found to be spread through exposed mucous membranes and uncovered eyes. Recent articles revealed a possibility of the same route of transmission used by SARS-CoV-2 in addition to respiratory droplets [12]. This suggestion is supported by a circumstantial finding after the infection of a member of the national panel with COVID-19 in Wuhan, despite having worn an N95 mask but without any eye protector. He later developed eye redness, followed by pneumonia, and was later diagnosed with COVID-19 [34]. The vertical spread of SARS-CoV-2 from mother to fetus or through breast milk is yet to be investigated [35].

\section{Intermediate host: The Malayan Pangolins}

The research elaborates that bats, which are the primary natural reservoirs of SARS-CoV-2, were not being sold at the Huanan seafood market. It suggests a high possibility of an unknown animal being the Intermediate host, which may have been sold in the market, hence infecting the terminal host, which is human [4]. As per research conducted on Malayan pangolins, a total of eighteen pangolins were investigated for the presence of SARSCoV-2 [36]. The genomic sequences obtained from these specimens revealed viruses that belonged to 2 sublineages of SARS-CoV-2 related viruses. However, they were still classified under the beta coronavirus genus of the Coronaviridae group of viruses. In addition to this, the genomic sequence of these viruses revealed a similarity of $85.5-92.4 \%$ to that of the new coronavirus, which is indicative of the possibility of pangolins being the intermediate hosts for COVID-19. 


\begin{tabular}{|c|c|c|c|}
\hline Type of specimen & Collection equipment & Shipment duration & Temperature for shipment \\
\hline Nasopharyngeal swab or oropharyngeal swab & Dacron Polyester flocked swabs & $\begin{array}{l}\leq 5 \text { days } \\
\text { More than } 5 \text { days }\end{array}$ & $\begin{array}{l}2-8^{\circ} \mathrm{C} \\
-70^{\circ} \mathrm{C} \text { in dry ice }\end{array}$ \\
\hline Bronchoalveolar lavage & Sterile container & $\begin{array}{l}\leq 2 \text { days } \\
\text { More than } 2 \text { days }\end{array}$ & $\begin{array}{l}2-8^{\circ} \mathrm{C} \\
-70^{\circ} \mathrm{C} \text { in dry ice }\end{array}$ \\
\hline $\begin{array}{l}\text { (Endo)tracheal aspirate Nasopharyngeal wash } \\
\text { Nasal wash/ aspirate }\end{array}$ & Sterile container & $\begin{array}{l}\leq 2 \text { days } \\
\text { More than } 2 \text { days }\end{array}$ & $\begin{array}{l}2-8^{\circ} \mathrm{C} \\
-70^{\circ} \mathrm{C} \text { in dry ice }\end{array}$ \\
\hline Sputum & Sterile container & $\begin{array}{l}\leq 2 \text { days } \\
\text { More than } 2 \text { days }\end{array}$ & $\begin{array}{l}2-8^{\circ} \mathrm{C} \\
-70^{\circ} \mathrm{C} \text { in dry ice }\end{array}$ \\
\hline $\begin{array}{l}\text { Tissue from biopsy or autopsy, } \\
\text { (Including tissues from the lung) }\end{array}$ & $\begin{array}{l}\text { Sterile container with VTM or } \\
\text { saline }\end{array}$ & $\begin{array}{l}\leq 24 \text { hours } \\
\text { More than } 24 \text { hours }\end{array}$ & $\begin{array}{l}2-8^{\circ} \mathrm{C} \\
-70^{\circ} \mathrm{C} \text { in dry ice }\end{array}$ \\
\hline Serum & $\begin{array}{l}\text { Serum separator tube ( } 3-5 \mathrm{ml} \text { of } \\
\text { adult blood to be collected). }\end{array}$ & $\begin{array}{l}\leq 5 \text { days } \\
\text { More than } 5 \text { days }\end{array}$ & $\begin{array}{l}2-8^{\circ} \mathrm{C} \\
-70^{\circ} \mathrm{C} \text { in dry ice }\end{array}$ \\
\hline Whole blood & Collection blood & $\begin{array}{l}\leq 5 \text { days } \\
\text { More than } 5 \text { days }\end{array}$ & $\begin{array}{l}2-8^{\circ} \mathrm{C} \\
-70^{\circ} \mathrm{C} \text { in dry ice }\end{array}$ \\
\hline Stool & Stool container & $\begin{array}{l}\leq 5 \text { days } \\
\text { More than } 5 \text { days }\end{array}$ & $\begin{array}{l}2-8^{\circ} \mathrm{C} \\
-70^{\circ} \mathrm{C} \text { in dry ice }\end{array}$ \\
\hline Urine & Urine collection container & $\begin{array}{l}\leq 5 \text { days } \\
\text { More than } 5 \text { days }\end{array}$ & $\begin{array}{l}2-8^{\circ} \mathrm{C} \\
-70^{\circ} \mathrm{C} \text { in dry ice }\end{array}$ \\
\hline
\end{tabular}

Adapted from WHO, 2020 Laboratory testing for 2019 novel coronavirus (2019-nCoV) in suspected human cases [41].

Moreover, given that two genetically resembling $\mathrm{CoV}$ lineages were identified in pangolins, they are crucial hosts for new coronavirus [36]. It has been observed that the N-terminal domain of SARA-CoV-2, RaTG13, and Guangxi pangolin coronaviruses exhibits the presence of motif, namely (YLTPGD), which is absent in the batrelated $\mathrm{CoV}$. The function of this new insertion may be the determination of the host range. It has also been found that the RBD of SARS-CoV-2 shows a greater similarity to pangolin viruses of the Guangdong lineage in comparison to RaTG13 [37].

\section{The incubation period of SARS- $\mathrm{CoV}-2$}

As per a study conducted on the transmission dynamics of new coronavirus, the mean incubation period has been estimated to be 5.2 days [38]. However, in a sample size of 425 patients, it was found that the incubation period varied from person to person [38]. Other studies supported the above finding by suggesting the length of the incubation period for SARS-CoV-2 to be 5.1 days [39]. Furthermore, it highlights that the infected persons are expected to show symptoms of COVID-19 in no longer than twelve days post-infection [40].

\section{Diagnostic testing of COVID-19}

Before proceeding towards laboratory investigations, it is essential to perform general and systemic examinations, mainly respiratory, for a patient presenting with the clinical symptoms of COVID-19. Specific guidelines have been proposed by the World Health Organization (WHO) which highlight on the specimens to be collected for testing, the laboratory investigations to be carried out and the biosafety guidance to be adhered to by medical professionals involved in the testing of COVID-19 [41].

\section{Specimen collection}

Given that COVID-19 predominantly involves the lungs, respiratory specimens should be collected. Nasopharyngeal and oropharyngeal swabs or washes are procured from the upper respiratory tract, Endotracheal aspirate or bronchoalveolar lavage or any sputum produced are collected for testing from the lower respiratory tract. Lower respiratory materials are procured specifically in severe cases of the disease. Respiratory specimens are considered highly specific for diagnosis; other samples like stool and blood can also be taken. However, the virus's rate and length of time to shed in the stool and urine have not yet been established. In patients deceased from COVID-19, lung tissue should be retrieved and preserved for future research.

Given the broad spectrum of symptoms experienced by COVID-19 patients, they should be diagnosed for the presence of other pathogenic organisms for respiratory diseases, using the existing investigations, in accordance with the guidelines provided for community-acquired pneumonia. However, if any other respiratory infection has already been identified, tests for COVID-19 should still be carried out, given the high probability of coinfections [41].

\section{Transport of Specimen}

The specimen should be transported to the laboratory immediately after collection under sterile conditions. Any delay in transport should be predicted and counteracted by using a viral transport medium (VTM), supplemented by antifungal and antibiotic agents, to preserve the specimen. If the samples collected are being tested in the country, they should be stored at $2-8{ }^{\circ} \mathrm{C}$. However, suppose shipment of these materials is required; in that case, specimens preserved in VTM should be transported at $20^{\circ} \mathrm{C}$ or more suitably at $-70^{\circ} \mathrm{C}$, considering that they should not be repetitively frozen and thawed. If VTM is 
unavailable, sterile saline can be used as a transport medium, with a temperature of storage at $2-8{ }^{\circ} \mathrm{C}$. Lastly, reliable communication channels should be established with the laboratory while the specimens are being delivered. It is vital that all the required information about the specimens is being conveyed explicitly [41].

More details about the transport of the specimen are illustrated in table 1.

\section{Tests}

i. Nucleic acid amplification tests (NAAT) for SARSCoV-2

The Principle of this test is to identify undistinguishable genes in the RNA virus of SARS-CoV-2, which are the genes coding for $\mathrm{N}, \mathrm{E}, \mathrm{S}$ proteins, and RNA dependent RNA polymerase.

These amplification tests also include real-time reversetranscription polymerase chain reaction (rRT-PCR) and nucleic acid sequencing only when required. This test should be safely conducted in a Class II biosafety cabinet by efficient laboratory personnel at a laboratory that meets a Biosafety Level 2 (BSL-2) standard [19]. The specimens for these amplification tests are mostly those procured from the lower and upper respiratory tract [41].

In areas with a high prevalence of COVID-19, a single confirmatory test like NAAT is considered the only differential procedure required to establish infection with COVID-19 [41]. However, negative results obtained from the first and more tests would not indicate that the patient is SARS-CoV-2 free. There is the possibility that errors could have occurred during the collection, handling, and transportation of the specimen or in the performance of the tests. The quality of the specimen can be questioned if the sample is collected too early or at a very late stage of infection. In these cases, both upper and lower respiratory specimens should be analyzed for SARS-CoV-2.

Moreover, the presence of both external and internal controls has been suggested for this test [41].

In an area where no COVID-19 cases have been observed, two non-identical genes from the SARS-CoV-2 genome are shared by other beta coronaviruses. These are done only if NAAT is used as a diagnostic test [18]. If the results for these two tests are found to be incongruous with each other, the virus should be sequenced from a more reliable NAAT assay [41]. Should be chosen, one of which should be particular only to SARS-CoV-2 and the other gene could be generic, It is to be noted that NAAT has also be recommended for medical officials or other personnel who have been working in contact with patients of COVID-19, specimens should be collected, and tests should be performed in the incubation period of the last recorded contact [41].

\section{ii. Serology}

If NAAT gives a negative result for a case that is profoundly related to COVID-19 infection, paired serum samples, both acute and convalescent, can be collected until the availability of serological assays arises. The first sample should be collected in the first week of illness, and the second can be procured after two to four weeks, giving sufficient time for a period of convalescence to be achieved [41].

\section{iii. Viral sequencing}

The sequencing of the virus genome is done from the virus isolated from patients of COVID-19. This is essential for observing any mutations in the virus genome, which might cause the failure of both diagnostic tests and treatment [41].

\section{iv. Viral culture}

As per the WHO guidelines, the virus's culture is a propagative work that can only be performed in a laboratory setting that meets Biosafety level 3 (BSL-3) standards [42]. However, it is not a preferred routine procedure for the diagnosis of COVID-19 [41].

Moreover, certain risks are associated with the viral cultures: the threat of any mutations in the genome, caused either deliberately or accidentally, resulting in increased infectiousness and spread of the virus. There could also be risks of co-infection with other coronaviruses [42].

The following non-specific tests of COVID-19 can also be conducted.

\section{Chest Imaging}

Chest radiography or chest CT scan can be performed when required. This is done to observe changes in the pulmonary interstitium and numerous small plaques on the lung periphery. These changes are observed in the early stage of the disease. They progress further from being unilateral to involve both lungs, usually distributed in the middle and outer zones, involving single and multiple lobes. Ground glass opacities are observed during the disease stage, and as recovery starts, a fibrous stripe may be observed. In severe cases, consolidation of the lung might occur [43].

\section{Haematological investigations}

These can be performed on a fresh blood sample from the patient.

Firstly, a total leukocyte count and differential leukocyte count can be conducted. In the initial stage of ailment, leukopenia may or may not be seen; however, as the disease progresses, there will be a drop in the number of lymphocytes. A significant drop in CD4+ and CD8+ T cells should be monitored for. These blood changes can be monitored at intervals of 3 days [43]. 
A research article based on the pathological findings of COVID-19 revealed a rise in the levels of Th17 subset of CD4 $\mathrm{T}$ cells, with an increase in the concentration of cytotoxic granules in the CD8 $\mathrm{T}$ cells. These specific changes reflect the degree of severe impairment to the immune system caused by SARS-CoV-2 [44].

Enzymes, such as muscle and liver enzymes, should be verified for any increase in their values. In some patients who tested positive for COVID-19, elevated levels of troponin and myohaemoglobin were observed. A rise in the value of troponin has been identified in certain critically ill patients. Nevertheless, in the majority of the patients, raised levels of erythrocyte sedimentation rate (ESR), high D dimer and C-reactive protein (CRP) were detected [43].

A study conducted on the retrospective analysis of COVID-19 patients reported a significant increase in serum ferritin level in critically ill COVID-19 patients. Interestingly, the ferritin level was the last parameter to be restored to its normal value. Hence, it cannot assess the progression and effectiveness of the treatment being provided.

Inflammatory factors, mainly serum soluble Interleukin 2(sIL2R), Interleukin 6, 10, and 1, and Tumour Necrosis Factor-alpha (TNF- $\alpha$ ), are elevated in the serum of COVID-19 patients. It has been found that sIL-2R can be used as a marker to gauge the prognosis of the disease.

However, interestingly, when compared to severe influenza, the proportions of IL-1 and IL-8 raised in COVID-19 is much lower, suggesting that their contribution to the cytokine storm elicited in COVID-19 is not as substantial as that in influenza [45].

\section{Discussion}

The genome of SARS-CoV-2 has its peculiarities as compared to its precedent MERS-CoV and SARS-CoV. The presence of furin cleavage site insertion at the junction S1-S2 of the spike glycoprotein molecule, a new protein in ORF3b, and novel polybasic cleavage site predicted O-linked glycans in the new coronavirus are the features that set it apart from its ancestral viruses [20,22]. The presence of these changes has been suggested to affect the increased infectiousness and host tropism of SARS-CoV-2, owing to which it could have a higher rate of transmissibility compared to MERS-Co and SARS$\mathrm{CoV}$. The transmissibility rate of SARS-CoV-2 has also been attributed to the severity of the clinical symptoms and viral load [28]. The possible inverse relationship between the severity of clinical symptoms and risk of community spread, if applied to COVID-19, explains how SARS-CoV-2 could be transmitted with greater ease within the community and across countries [28]. The higher rate of transmissibility of COVID-19 has also been attributed to viral loads at the time when symptoms start appearing. Given that for COVID-19, the viral dose starts to decrease even before the onset of mild symptoms, the community spread of this new member of the CoV family is easier, as compared to SARS, in which the virus has its peak shedding only after 10 days of the initial beginning of symptoms, hence making SARS-CoV less transmissible virus [28].

According to various genomic studies, the source of COVID-19 infection has been substantially proven to be bats. However, there has also been an ongoing debate of Malayan Pangolins as being the intermediate host for the spread of SARS-CoV-2, owing to their significant similarity between the coronaviruses isolated from them and SARS-CoV-2 [36, 37]. However, the tiny population size, endangered status, and solitary life pattern of Malayan Pangolins do not coincide with the high transmission rate of the COVID-19. Hence, their role in the spread of COVID-19 still needs further investigation. The evolution of this new viral offender has been studied by many researchers $[4,6,30,45]$. The possible mechanism of evolution suggested is recombination, which has been questioned in many research papers $[4,6]$. On the contrary, other papers have mentioned the possibility of SARS-CoV-2 being in circulation among the human population for a questionable period, which later acquired some significant mutations leading to its development as a potentially infectious and virulent virus. Hence, the evolution of SARS-CoV-2 needs to be further researched [45].

\section{Conclusion}

COVID-19 is the third outbreak of a pathogenic human coronavirus, after MERS and SARS. However, its impact has been more disastrous than the preceding viruses. Its high rate of transmissibility has taken a toll on citizens' personal and professional lives globally. The peculiarities of SARS-CoV-2, regarding its genomic uniqueness and the role of Malayan pangolins as intermediate hosts, still demands more research to determine the degree to which they partake in the generation of the pathogenicity and infectiousness of the virus.

\section{Abbreviations}

Baby Hamster Kidney fibroblasts (BHK cells), Biosafety level 2 (BSL-2), Biosafety level 3 (BSL-3), Bovine coronavirus (BCV), Coronaviridae $(\mathrm{CoV})$, Coronavirus disease 2019 (COVID 19), Hemagglutinin esterase glycoprotein (HE), Human coronavirus (HCoV), Human Angiotensin converting enzyme 2 receptor (ACE2/hACE2), Integral membrane protein ( $\mathrm{M}$ protein), Interleukin 1(IL-1), Interleukin 8 (IL-8), Interferon (IFN), Middle Eastern respiratory syndrome coronavirus (MERS-CoV), Nucleic acid amplification tests (NAAT), non-structural protein(nsp), Open reading frame (ORF), Receptor binding motif (RBM), Reproductive number (R0), real-time reversetranscription polymerase chain reaction (rRt- PCR), Receptor binding domain (RBD), Small Membrane protein (E protein), Spike glycoprotein Membrane (S protein), 
Severe acute respiratory syndrome coronavirus 2 (SARS$\mathrm{CoV}-2)$, Severe acute respiratory syndrome coronavirus (SARS-CoV), Soluble Interleukin 2 receptor (IL-2R), Tumor Necrosis Factor alpha (TNF Alpha), Viral Transport Medium (VTM), World Health Organization (WHO)

\section{Acknowledgments}

We extend our intense gratitude to the Chairman Mr. RPN Singh and Prof. Namrata Chhabra, Principal In charge, Sir Seewoosagur Ramgoolam Medical College, Belle Rive, Mauritius, for providing us with huge support and guidance to conduct the research study effectively.

\section{Authors' contribution}
a. Study planning: IB, PM
b. Manuscript writing: PM, IB, AK, JR, AS, NDR
c. Manuscript revision: PM, IB
d. Final approval: PM, IB, AK, JR, AS, NDR
e. Agreement to be accountable for all aspects of the work: PM, IB, AK, JR, AS, NDR

\section{Funding}

There was no funding for this work.

\section{Availability of data and materials}

All data and materials available as part of the article, and no additional source data are required.

\section{Competing interests}

There is no conflict of interest for any author of this manuscript.

\section{Publisher's Note}

NHRS remains neutral with regard to jurisdictional claims in published maps and institutional affiliations.

The publisher shall not be legally responsible for any types of loss, actions, claims, proceedings, demand or costs or damages whatsoever or howsoever caused arising directly or indirectly in connection with or arising out of the use of this material.

\section{Author information}

${ }^{1}$ Poornasha Mohabeer, 2nd Professional medical student, Sir Seewoosagur Ramgoolam Medical College, Mauritius ORCID

${ }^{2}$ Dr Indrajit Banerjee, Associate Professor, Department of Pharmacology, Sir Seewoosagur Ramgoolam Medical College, Mauritius ORCID

${ }^{3}$ Abhishek Kashyap, 2nd Professional medical student, Sir Seewoosagur Ramgoolam Medical College, Mauritius $\underline{\text { ORCID }}$
${ }^{4}$ Ananya Shukla, 2nd Professional medical student, Sir Seewoosagur Ramgoolam Medical College, Mauritius ORCID

${ }^{5}$ Jared Robinson, 2nd Professional medical student, Sir Seewoosagur Ramgoolam Medical College, Mauritius ORCID

${ }^{6}$ Nikhil D. Ramdhan, Assistant Professor, Department of Microbiology, Sir Seewoosagur Ramgoolam Medical College, Mauritius

ORCID

\section{References}

1. Li X, Geng M, Peng Y, Meng L, Lu S. Molecular immune pathogenesis and diagnosis of COVID19. J Pharm Anal. 2020;10(2):102-108. https://doi.org/10.1016/j.jpha.2020.03.001

2. Tan W, Zhao X, Ma X, Wang W, Niu P, Xu W et al. A Novel Coronavirus Genome Identified in a Cluster of Pneumonia Cases - Wuhan, China 2019-2020. China CDC Weekly. 2020;2(4):6162.

https://doi.org/10.46234/ccdcw2020.017

3. Coronavirus disease (COVID-19) - World Health Organization [Internet]. Who.int. 2020 [cited 24 October 2020]. Available from: https://www.who.int/emergencies/diseases/novelcoronavirus-

2019?gclid=CjwKCAjw_NX7BRA1EiwA2dpg0t FcQwY1XD6fh677Mj3fa2EMogG4TTdSzGSOg Rm3h740tVknUxVYKhoC16wQAvD_BwE

4. Lu R, Zhao $\mathrm{X}$, $\mathrm{Li} \mathrm{J}$, et al. Genomic characterisation and epidemiology of 2019 novel coronavirus: implications for virus origins and receptor binding. Lancet. 2020;395(10224):565-574. https://doi.org/10.1016/S0140-6736(20)30251-8

5. Shereen MA, Khan S, Kazmi A, Bashir N, Siddique R. COVID-19 infection: Origin, transmission, and characteristics of human coronaviruses. J Adv Res. 2020;24:91-98. https://doi.org/10.1016/j.jare.2020.03.005

6. Helmy Y, Fawzy M, Elaswad A, Sobieh A, Kenney S, Shehata A. The COVID-19 Pandemic: A Comprehensive Review of Taxonomy, Genetics, Epidemiology, Diagnosis, Treatment, and Control. Journal of Clinical Medicine. 2020;9(4):1225.

https://doi.org/10.3390/jcm9041225

7. Zhu N, Zhang D, Wang W, et al. A Novel Coronavirus from Patients with Pneumonia in China, 2019. N Engl J Med. 2020;382(8):727-733. https://doi.org/10.1056/NEJMoa2001017 
8. Petrosillo N, Viceconte G, Ergonul O, Ippolito G, Petersen E. COVID-19, SARS and MERS: are they closely related?. Clin Microbiol Infect. 2020;S1198-743X(20)30171-3. https://doi:10.1016/j.cmi.2020.03.026

9. Lai MM, Cavanagh D. The molecular biology of coronaviruses. Adv Virus Res. 1997;48:1-100. https://doi.org/10.1016/S0065-3527(08)60286-9

10. Lu G, Wang Q, Gao GF. Bat-to-human: spike features determining 'host jump' of coronaviruses SARS-CoV, MERS-CoV, and beyond. Trends Microbiol. 2015;23(8):468-478. https://doi.org/10.1016/j.tim.2015.06.003

11. Mousavizadeh L, Ghasemi S. Genotype and phenotype of COVID-19: Their roles in pathogenesis. J Microbiol Immunol Infect. 2020 Mar 31.

https://doi.org/10.1016/j.jmii.2020.03.022

12. Wu A, Peng Y, Huang B, Ding X, Wang X, Niu $P$ et al. Genome Composition and Divergence of the Novel Coronavirus (2019-nCoV) Originating in China. Cell Host \& Microbe. 2020;27(3):325328.

https://doi.org/10.1016/j.chom.2020.02.001

13. Banerjee I, Mohabeer P, Shukla A, Kashyap A, Robinson J. COVID-19: Recent advances in epidemiology, virology, etiopathogenesis, clinical trials and vaccine development. J Biomed Sci, 2020; 7(1), 18-27.

https://doi.org/10.3126/jbs.v7i1.29849

14. Chen N, Zhou M, Dong X, Qu J, Gong F, Han Y et al. Epidemiological and clinical characteristics of 99 cases of 2019 novel coronavirus pneumonia in Wuhan, China: a descriptive study. The Lancet. 2020;395(10223):507-513. https://doi.org/10.1016/S0140-6736(20)30211-7

15. Ceraolo C, Giorgi F. Genomic variance of the 2019-nCoV coronavirus. Journal of Medical Virology. 2020;92(5):522-528. https://doi.org/10.1002/jmv.25700

16. Angeletti S, Benvenuto D, Bianchi M, Giovanetti M, Pascarella S, Ciccozzi M. COVID-2019: The role of the nsp2 and nsp3 in its pathogenesis. Journal of Medical Virology. 2020;92(6):584588.

https://doi.org/10.1002/jmv.25719

17. Krichel B, Falke S, Hilgenfeld R, Redecke L, Uetrecht C. Processing of the SARS-CoV pp1a/ab nsp7-10 region. Biochemical Journal. 2020;477(5):1009-1019.

https://doi.org/10.1042/BCJ20200029

18. Lu R, Zhao X, Li J, Niu P, Yang B, Wu H et al. Genomic characterisation and epidemiology of 2019 novel coronavirus: implications for virus origins and receptor binding. The Lancet. 2020;395(10224):565-574.

https://doi.org/10.1016/S0140-6736(20)30251-8

19. Wan Y, Shang J, Graham R, Baric RS, Li F. Receptor Recognition by the Novel Coronavirus from Wuhan: an Analysis Based on DecadeLong Structural Studies of SARS Coronavirus. J Virol. 2020 Mar 17;94(7):e00127-20. https://doi.org/10.1128/JVI.00127-20

20. Andersen K, Rambaut A, Lipkin W, Holmes E, Garry R. The proximal origin of SARS-CoV-2. Nature Medicine. 2020;26(4):450-452 https://doi.org/10.1038/s41591-020-0820-9

21. Walls A, Park Y, Tortorici M, Wall A, McGuire A, Veesler D. Structure, Function, and Antigenicity of the SARS-CoV-2 Spike Glycoprotein. Cell. 2020;181(2):281-292.e6. https://doi.org/10.1016/j.cell.2020.02.058

22. Zhou H, Chen X, Hu T, Li J, Song H, Liu Y et al. A Novel Bat Coronavirus Closely Related to SARS-CoV-2 Contains Natural Insertions at the S1/S2 Cleavage Site of the Spike Protein. Current Biology. 2020;30(11):2196-2203.e3. https://doi.org/10.1016/j.cub.2020.05.023

23. Klenk H, Garten W. Host cell proteases controlling virus pathogenicity. Trends in Microbiology. 1994;2(2):39-43. https://doi.org/10.1016/0966-842X(94)90123-6

24. Steinhauer D. Role of Hemagglutinin Cleavage for the Pathogenicity of Influenza Virus. Virology. 1999;258(1):1-20. https://doi.org/10.1006/viro.1999.9716

25. Khan S, Fielding B, Tan T, Chou C, Shen S, Lim $\mathrm{S}$, et al. Over-expression of severe acute respiratory syndrome coronavirus $3 \mathrm{~b}$ protein induces both apoptosis and necrosis in Vero E6 cells. Virus Research. 2006;122(1-2):20-27. https://doi.org/10.1016/j.virusres.2006.06.005

26. Kopecky-Bromberg S, Martínez-Sobrido L, Frieman M, Baric R, Palese P. Severe Acute Respiratory Syndrome Coronavirus Open Reading Frame (ORF) 3b, ORF 6, and Nucleocapsid Proteins Function as Interferon Antagonists. Journal of Virology. 2006;81(2):548-557. https://doi.org/10.1128/JVI.01782-06

27. Liu Y, Gayle AA, Wilder-Smith A, Rocklöv J. The reproductive number of COVID-19 is higher compared to SARS coronavirus. J Travel Med. 2020;27(2):taaa021. https://doi.org/10.1093/jtm/taaa021

28. Xie M, Chen Q. Insight into 2019 novel coronavirus - An updated interim review and 
lessons from SARS-CoV and MERS-CoV. Int J Infect Dis. 2020;94:119-124.

https://doi.org/10.1016/j.ijid.2020.03.071

29. Zhou $\mathrm{P}$, Yang $\mathrm{X}$, Wang $\mathrm{X}$, Hu B, Zhang L, Zhang $\mathrm{W}$, et al. A pneumonia outbreak associated with a new coronavirus of probable bat origin. Nature. 2020;579(7798):270-273. https://doi.org/10.1038/s41586-020-2012-7

30. Liu S, Saif L, Weiss S, Su L. No credible evidence supporting claims of the laboratory engineering of SARS-CoV-2. Emerging Microbes \& Infections. 2020;9(1):505-507. https://doi.org/10.1080/22221751.2020.1733440

31. Bourouiba L. Images in clinical medicine. A Sneeze. N Engl J Med. 2016;375(8):e15. https://doi.org/10.1056/NEJMicm1501197

32. Ningthoujam R. COVID 19 can spread through breathing, talking, study estimates. Curr Med Res Pract. 2020 May-Jun;10(3):132-133. https://doi.org/10.1016/j.cmrp.2020.05.003

33. Zheng J. SARS-CoV-2: an Emerging Coronavirus that Causes a Global Threat. Int J Biol Sci. 2020;16(10):1678-1685. https://doi.org/10.7150/ijbs.45053

34. Chen Z, Fu J, Shu Q, Chen Y, Hua C, Li F, et al. Diagnosis and treatment recommendations for pediatric respiratory infection caused by the 2019 novel coronavirus. World Journal of Pediatrics. 2020;16(3):240-246.

https://doi.org/10.1007/s12519-020-00345-5

35. Lam TT, Jia N, Zhang YW, Shum MH, Jiang JF, Zhu HC, et al. Identifying SARS-CoV-2-related coronaviruses in Malayan pangolins. Nature. 2020 Jul;583(7815):282-285. https://doi.org/10.1038/s41586-020-2169-0

36. Mohabeer P, Shukla A, Robinson J, Kashyap A, Ramdhan ND, Banerjee, I. Malayan Pangolins: The missing piece to the puzzle of COVID-19. Quest International Journal of Medical and Health Sciences. 2020; 3(1), 4-6. https://doi.org/10.5281/zenodo.3946094

37. Li Q, Guan X, Wu P, Wang X, Zhou L, Tong Y, et al. Early Transmission Dynamics in Wuhan, China, of Novel Coronavirus-Infected Pneumonia. N Engl J Med. 2020 Mar 26;382(13):1199-1207. https://doi.org/10.1056/NEJMoa2001316

38. Kang S, Peng W, Zhu Y, Lu S, Zhou M, Lin W, et al. Recent progress in understanding 2019 novel coronavirus (SARS-CoV-2) associated with human respiratory disease: detection, mechanisms and treatment. Int $\mathrm{J}$ Antimicrob Agents. 2020 May;55(5):105950. https://doi.org/10.1016/j.ijantimicag.2020.10595 $\underline{0}$

39. Lauer SA, Grantz KH, Bi Q, Jones FK, Zheng Q, Meredith HR, et al. The Incubation Period of Coronavirus Disease 2019 (COVID-19) From Publicly Reported Confirmed Cases: Estimation and Application. Ann Intern Med. 2020;172(9):577-582.

https://doi.org/10.7326/M20-0504

40. Jin YH, Cai L, Cheng ZS, Cheng H, Deng T, Fan YP, et al. A rapid advice guideline for the diagnosis and treatment of 2019 novel coronavirus (2019-nCoV) infected pneumonia (standard version). Mil Med Res. 2020;7(1):4.

https://doi.org/10.1186/s40779-020-0233-6

41. Xu Z, Shi L, Wang Y, Zhang J, Huang L, Zhang $\mathrm{C}$, et al. Pathological findings of COVID-19 associated with acute respiratory distress syndrome. Lancet Respir Med. 2020;8(4):420-422. doi:10.1016/S22132600(20)30076-X

https://doi.org/10.1016/S2213-2600(20)30076-X

42. Li Y, Hu Y, Yu J, Ma T. Retrospective analysis of laboratory testing in 54 patients with severeor critical-type 2019 novel coronavirus pneumonia. Lab Invest. 2020;1-7. https://doi.org/10.1038/s41374-020-0431-6

43. Robinson J, Banerjee I, Sathian, B. COVID-19: Is herd immunity the answer? Journal of Advances in Internal Medicine. 2020;9(2), 94-97. https://doi.org/10.3126/jaim.v9i2.32834

44. Banerjee I, Robinson J, Sathian B, van Teijlingen E. South Africa and its COVID-19 prohibition predilection. Nepal Journal of Epidemiology.2020;10(3),874-877. https://doi.org/10.3126/nje.v10i3.31543

45. Banerjee I, Robinson J, Kashyap A, Mohabeer P, Shukla A, Leclézio A. The changing pattern of COVID-19 in Nepal: A Global concern- A Narrative Review. Nepal J Epidemiol. 2020 Jun 30;10(2):845-855.

https://doi:10.3126/nje.v10i2.29769 